\title{
A DUALIDADE NA RELAÇÃO SOCIEDADE-NATUREZA ENTRE OS INDÍGENAS PARESI E OS FAZENDEIROS DO ENTORNO SOBRE A PAISAGEM
}

\author{
Nicodemos Misquita de Oliveira \\ Universidade Federal de Mato Grosso - UFTM \\ Pós-Graduação em Geografia \\ Cuiabá, MT, Brasil \\ nicooliveira29@gmail.com \\ José Carlos Ugeda Junior \\ Universidade Federal de Mato Grosso - UFTM \\ Cuiabá, MT, Brasil \\ ugedajunior@gmail.com
}

\begin{abstract}
RESUMO
O estudo apresenta uma análise da paisagem na bacia hidrográfica do Rio Verde, território indígena Paresi em Tangará da Serra - Mato Grosso. Pautada no método geossistêmico somado ao viés crítico da geografia. Envolveu estudos sobre concepções diferenciadas na relação sociedade-natureza entre os Paresi-Haliti e os fazendeiros do entorno. Assinalada pela resistência dos indígenas frente ao processo de homogeneização da paisagem. O resultado cartográfico do uso e ocupação do solo nos últimos trinta anos revelou uma paisagem muito alterada no entorno da terra indígena, marcada pelas geometrias das plantações de commodities de grãos. Já no território indígena a vegetação natural foi mantida praticamente conservada. Entrevistas com os fazendeiros e indígenas apontaram incompatibilidades nos usos múltiplos do rio. Rituais tradicionais foram comprometidos, pois muitos locais sagrados ficaram situados fora do território delimitado, em áreas particulares. Houve também uma diminuição dos animais de caça pela perda de habitat. O território indígena Paresi representa, juntamente com outros territórios indígenas, a riqueza da heterogeneidade cultural e também acabaram assumindo um importante papel na preservação dos biomas no estado.
\end{abstract}

Palavras-chave: Bacia hidrográfica do Rio Verde. Índios Paresi. Relação sociedadenatureza indígena.

\section{DUALITY IN THE SOCIETY-NATURE RELATIONSHIP BETWEEN THE PARES INDIGENOUS PEOPLE AND THE ENVIRONMENTAL FARMERS ABOUT THE LANDSCAPE}

\begin{abstract}
The study presents an analysis of the landscape in the basin of Rio Verde, Paresi indigenous territory in Tangará da Serra - Mato Grosso. Guided by the geosystemic method added to the critical bias of geography. It involved studies on differentiated conceptions in the society-nature relationship between the Paresi (Haliti) and the surrounding farmers. It is marked by the indigenous resistance to the process of homogenization of the landscape. The cartographic result of land use and occupation over the last thirty years has revealed a much-altered landscape around indigenous land, marked by the geometries of grain commodity plantations. Already in the indigenous territory the natural vegetation was maintained relatively conserved. Interviews with farmers and indigenous people pointed out incompatibilities in the multiple uses of the river. Traditional rituals were compromised as there are many sacred sites located outside the bounded territory in particular areas. There is also a decrease in animals hunting to loss of habitat. The Paresi indigenous territory, together with other indigenous territories, represents the wealth of cultural heterogeneity and also an important representation in the preservation of biomes in the state.
\end{abstract}

Keywords: Rio Verde watershed. Paresi indians. Indigenous society-nature relationship. 


\section{INTRODUÇÃO}

O presente trabalho parte de uma manifestação de grande descontentamento do Grupo Paresi Kozarini da aldeia Rio Verde com as transformações no rio de mesmo nome, sofridas ao longo das últimas décadas. E vista pelo olhar dos indígenas como um fenômeno de degradação ambiental que afeta a vida coletiva em seu território tradicional.

Diante da situação levantada, iniciou-se por meio de trabalhos em campo na área da bacia que margeia a aldeia, a verificação dos pontos considerados pelo grupo como de maior estágio de degradação ambiental, visando subsidiar estudos de planejamento ambiental mais aprofundados sobre os processos atuantes na modificação da paisagem.

A análise da paisagem da bacia hidrográfica está intrinsecamente ligada à história do contato entre os indígenas e não indígenas (imóti). Intensificada a partir das décadas de $1960 \mathrm{com}$ avanço da fronteira agrícola no estado rumo a região amazônica, alterando os limites e surrupiando territórios tradicionais com o aval governamental.

Estudos realizados por diversos pesquisadores revelam prejuízos socioambientais acumulados ao longo desse processo de aproximação. A degradação ambiental foi ocorrendo juntamente com grande perda de território e sua transformação em fazendas. A abertura de extensas rodovias, a exemplo da BR-364, teve um papel fundamental, juntamente com as políticas e programas governamentais de incentivo agrícola, na atração e ocupação por imigrantes na chapada e planalto do Parecis. O território indígena se viu cercado por latifúndios do agronegócio, propiciando ao longo do tempo profundas mudanças socioeconômicas ao grupo.

Foi então realizada uma análise da paisagem da bacia hidrográfica através da evolução espaço temporal que contém as variações na cobertura e o uso do solo em um período de 30 anos. 0 que auxilia no entendimento das alterações socioambientais ocorridas no território indígena nas últimas décadas. Executada por meio de investigações em campo, interpretação das imagens da Missão Topográfica Radar Shuttle (SRTM), satélite landsat-5 e Landsat-8, em software de informação geográfica.

Conforme foram se devolvendo as entrevistas com os indígenas e não indígenas sobre os problemas ambientais apresentados no rio Verde e através da revisão da literatura, a pesquisa tomou um caminho mais aprofundado sobre o papel dos objetos e ações dos sujeitos envolvidos na dinâmica da paisagem. Sendo reveladores do atual cenário da bacia hidrográfica, com degradações ambientais interferindo na vida cotidiana dos indígenas.

Dessa forma, a construção da pesquisa levou ao estudo da relação dos Paresi e dos não indígenas (fazendeiros) do entorno com a paisagem da bacia hidrográfica do Rio Verde, entendendo que se tratam de duas sociedades distintas, e que se relacionam de maneira diferenciada com a natureza.

Considera-se que a sociedade está inserida como matéria funcional dentro do sistema paisagem, porém desempenha um papel de um ser social complexo, um ator protagonista e coadjuvante da transformação da paisagem. A sociedade então se manifesta alterando as estruturas do geossistema e compondo divergências de relações entre sociedades diferenciadas em uma unidade da paisagem.

A pesquisa visa demonstrar o caráter dialético entre natureza e a sociedade e as contradições entre os entes sociais indígenas e não indígenas no uso do espaço. Devido a paisagem ser vista de maneira distinta por esses dois atores com suas diferenças socioculturais, acaba formando concepções e ações conflitantes sobre um mesmo meio físico.

A sociedade indígena Paresi demonstrou uma relação com a natureza bem definida por suas concepções de mundo. E estas são inseparáveis da paisagem que the foi construída ao longo de gerações por diversos grupos Haliti e também influenciados por vários vizinhos de outras etnias indígenas que compunham a heterogeneidade cultural da Chapada do Parecis e regiões limítrofes.

Portanto, a dinâmica da paisagem também é expressa pela dinâmica socioambiental indígena ao longo do tempo, pela continuação dos valores culturais herdados dos seus antepassados, 
dando vida e sentido, através da sua perspectiva cosmologia, aos ambientes socialmente construídos.

\section{METODOLOGIA}

A realização da presente pesquisa está pautada no método geossistêmico somado ao viés crítico da geografia, conhecido como materialismo histórico e dialético, com enfoque nas relações entre a sociedade e a natureza. Para tanto estão sendo utilizando conceitos balizadores da geografia como: espaço, paisagem e território.

E que teve como embasamento teórico-metodológico a Geoecologia das Paisagem de Rodriguez, Silva e Cavalcanti (2004), da qual se construiu uma lógica metodológica que articulasse paisagem natural, social e cultural. Com a contribuição de diversos autores, entres eles: Bertrand (1971), Gonçalves (2002), Santos (2006), SMITH, N (1987), Viveiros de Castro (2004), e outros.

A paisagem então é considerada como uma porção do espaço definida, "o resultado da combinação dinâmica, portanto, instável, de elementos físicos, biológicos e antrópicos, reagindo dialeticamente uns sobre os outros em um conjunto único e indissociável, em perpétua evolução." (BERTRAND, 1971, p. 141)

Nesse viés a investigação da bacia hidrográfica do Rio Verde pautou-se então pelo esclarecimento de tendências no uso e ocupação das terras da região que influenciam na situação socioambiental da paisagem.

Por meio da metodologia da geoecologia utilizada por Rodriguez, Silva e Cavalcanti (2004) procurou-se conhecer melhor a estrutura física da paisagem, enxergar os movimentos regulares e dirigidos dos objetos e sujeitos que provocam modificações quantitativas e qualitativas no meio geográfico.

Os procedimentos metodológicos consistiram em etapas de levantamento de dados e realização das análises espaciais e temporais, utilizando-se de ferramentas cartográficas com auxílio do sistema de informações geográficas (SIG).

Para a mudança no uso e ocupação do solo ao longo do tempo foram obtidas imagens orbitais Landsat pelo banco de dados The United States Geological Survey (USGS) e no catálogo do Instituto Nacional de Pesquisas Espaciais (INPE). Sendo que para preenchimento de toda área da bacia hidrográfica foram selecionadas as imagens da órbita-Ponto 228/069 e 228/070, do sensor Landsat TM 5 de 18/05/1986. E também para mesma faixa, o sensor Lansat-8 (OLI) de resolução espacial de 30 metros multiespectral, de 23/06/2016.

Os produtos cartográficos permitiram realizar uma síntese da estrutura da bacia, indicativa de potencialidades e limitações de uso da unidade da paisagem, e relaciona-la a reação da paisagem as diferentes formas de apropriação do espaço pelas culturas indígenas e não indígenas.

Através de estudos, entrevistas nas fazendas do entorno e nas aldeias Rio Verde, Kotitiko, África, Kamaê e Estivadinho, pode se elucidar a respeito da situação da paisagem na visão dessas comunidades, como elas a percebem, a utilizam e também atuam na sua modificação. Trabalhar com a percepção da sociedade Paresi em torno da natureza requereu conhecer um ritmo sociocultural diferenciado e enxergar na paisagem um mundo repleto de simbolismos próprios da cultura Haliti.

\section{RESULTADOS E DISCUSSÕES}

A paisagem do povo Haliti é vivida por meio de "mediações natureza e sociedade" Giannini (1994 p.151) repleta de valorizações simbólicas. Que segundo os indígenas, tudo o que é fruto da caça, pesca e agricultura tradicional tem que ser celebrado e oferecido antes de ser consumido. A desobediência pode levar a acontecimentos negativos para vida do indígena e 
da sua família. O que já demonstra uma diferença do ritmo do tempo da aldeia, e de sua unicidade com a natureza.

Na paisagem do cerrado estão contidas a natureza com suas formas herdadas dos demiurgos, Wazare e seus irmãos e irmãs ao povo Haliti. Existe um ambiente de cumplicidade com meio natural, sendo infindáveis as dimensões simbólicas que criam o sentimento de pertencimento com o seu território tradicional.

Entre elas, o conhecimento tradicional sobre os ciclos naturais no preparo do roçado que leva em consideração os sinais do céu. O solo é adubado naturalmente, onde a raiz da mandioca alimenta o corpo físico e são também oferecidas aos espíritos protetores em sinal de agradecimento pelo sucesso da colheita, são rituais que trazem união entre os familiares.

$\mathrm{O}$ atual cenário da paisagem passa pelo relacionalismo da unicidade dos Haliti com a natureza, revelador do seu modo de organização, vivência do espaço e de razões cosmocêntricas que os impulsionam a reivindicar melhorias socioambientais para seu povo.

Já na sociedade não indígena, a história da sua cultura revela o tratamento de supremacia humana sobre a natureza formando um Deus pós-Socrático que é a imagem e semelhança do homem, "o sujeito em oposição ao objeto, a natureza". (GONÇALVES, 2006, p.33)

Considera-se então a existência de uma dualidade entre as sociedades elencadas em torno da natureza, que são por vezes antagônicas. Apresenta-se na sociedade não indígena a experiência da natureza, que apesar de ter um fundamento comum, é dita por Smith (1988) como de concepção extremamente complexa e por vez contraditória.

Uma natureza apresentada com uma dualidade material e espiritual. E que apesar da infinidade de significados que isso possa conceber, sua heterogeneidade é organizada em um dualismo que domina o conceito de natureza: o da sua externalidade e de seu caráter universal. (SMITH, 1988, p.28)

Em meio a esses contrastes ontológicos e epistemológicos se apresenta o atual momento de hegemonia das commodities na bacia do Rio Verde e da Chapada do Parecis, que sofre um custo socioambiental alto da homogeneização da paisagem pela monocultura. $O$ que tem ocasionado um desequilíbrio no ordenamento territorial pela eliminação da diferença na paisagem. Diante de uma dialética entre a retração da diversidade socioambiental e da infindável necessidade de expansão da produção para manter-se competitiva no mercado global e acumular mais capital.

Neste cenário, a relação com a natureza por parte dos fazendeiros permanece deficiente, se realizando apenas como meio de transformação da mercadoria, um recurso natural a ser trabalhado, explorado pelo capital. $O$ que está alheio a isso é relegado a segundo plano, estranho ao objetivo maior, visto como sinônimo de desperdício de recurso.

O impulso produtivo que movimenta essa transformação, conforme colocado por Santos (2006), não é local. A produção já foi negociada antes mesmo de existir de fato. Ela não tem pátria, é extraterritorial. Não tendo o capital compromisso com a realidade ambiental local, nem a preocupação de se adequar as diferentes culturas que dividem o mesmo espaço.

Tal fato segundo Santos (2008) é um gerador de tensão na paisagem, onde são encontrados objetos com idades diferentes.

A paisagem não se cria de uma só vez, mas por acréscimos, substituições; a lógica pela qual se fez um objeto no passado era a lógica da produção daquele momento. Uma paisagem é uma escrita sobre a outra, é um conjunto de objetos que têm idades diferentes, é uma herança de muitos diferentes momentos. (SANTOS, 2008, p. 73)

Demonstrado pelo recorte espacial da unidade da paisagem da bacia hidrográfica do Rio Verde, através do uso dos recursos ambientais e ocupação deste espaço, as custas das contradições intrínsecas ao comportamento diferenciado da sociedade Paresi e dos não indígenas na paisagem natural. 
E para acompanhar os padrões das modificações ocorridas ao longo dos últimos 30 (trinta) anos na bacia do rio Verde, utiliza-se das análises espaço-temporais, entendidas como instrumentos fundamentais na simulação de cenários, no relacionamento do grau e ritmo da alteração da paisagem natural em resposta ao estudo socioambiental.

O uso das imagens Landsat-5 e Landsat-8 dos anos de 1986 e 2016 foram escolhidas em um período seco do ano, de 18/05/1986 e 23/06/2016, respectivamente, com resolução espacial de 30 metros. Utilizadas para mapear a cobertura do solo e realizar a quantificação em seis classes.

A tabela 1 apresenta a quantificação das classes e o percentual de representatividade na bacia por tipo de cobertura e uso do solo, mostrando a evolução da paisagem na bacia entre os anos de 1986 e 2016.

De acordo com visita a campo, a área delimitada da bacia para os distintos períodos foi classificada em seis classes de análise comparativa da evolução espaço/temporal: corpos d'água, formação florestal, formação savânica, formação campestre, agropecuária e solo exposto.

TABELA 1 - Quantificação das classes por tipo de cobertura e uso do solo.

\begin{tabular}{lccccc}
\hline Cobertura e uso do solo & \multicolumn{2}{c}{1986} & \multicolumn{2}{c}{2016} & Diagnóstico \\
\hline & Área km2 & Área \% & Área km2 & Área \% & \\
\hline Corpos d'água & 29,20 & 1,22 & 9,64 & 0,41 & Redução \\
\hline Formações florestais & 258,79 & 10,78 & 198,04 & 8,30 & Redução \\
\hline Formações savânicas & 819,99 & 34,14 & 128,48 & 5,38 & Redução \\
\hline Formações campestres & 870,73 & 36,26 & 955,93 & 40,05 & Aumento \\
\hline Agropecuária & 408,24 & 16,99 & $1.080,39$ & 45,26 & Expansão \\
\hline Solo exposto & 14,58 & 0,61 & 14,37 & 0,61 & Nulo \\
\hline Total & $2.401,53$ & 100 & $2.386,83$ & 100 & \\
\hline
\end{tabular}

Fonte - OLIVEIRA (2018, p. 120).

A definição das classes da formação vegetacional foram baseadas na descrição das principais características fitofisionômicas definidas pela Agência de Informação da Embrapa (2017). Sendo onze os tipos principais de vegetação para o bioma Cerrado, e ainda se for adotado os subtipos são considerados 25 tipos de vegetação.

a) Formações florestais: (Mata Ciliar, Mata de Galeria, Mata Seca e Cerradão).

b) Formações savânicas: (Cerrado sentido restrito, Parque de Cerrado, Palmeiral e Vereda).

c) Formações campestres: (Campo Sujo, Campo Limpo e Campo Rupestre).

$\mathrm{Na}$ comparação das imagens dos anos de 1986 e 2016, constata-se que o avanço da área agrícola na bacia do Rio Verde coincide com o traçado da BR-364. O polígono da bacia hidrográfica aparece como uma continuidade da paisagem que compreendem o complexo de fazendas da Chapada dos Parecis destinada à produção de commodities do agronegócio. 
Figura 1 - Uso e cobertura do solo 1986.

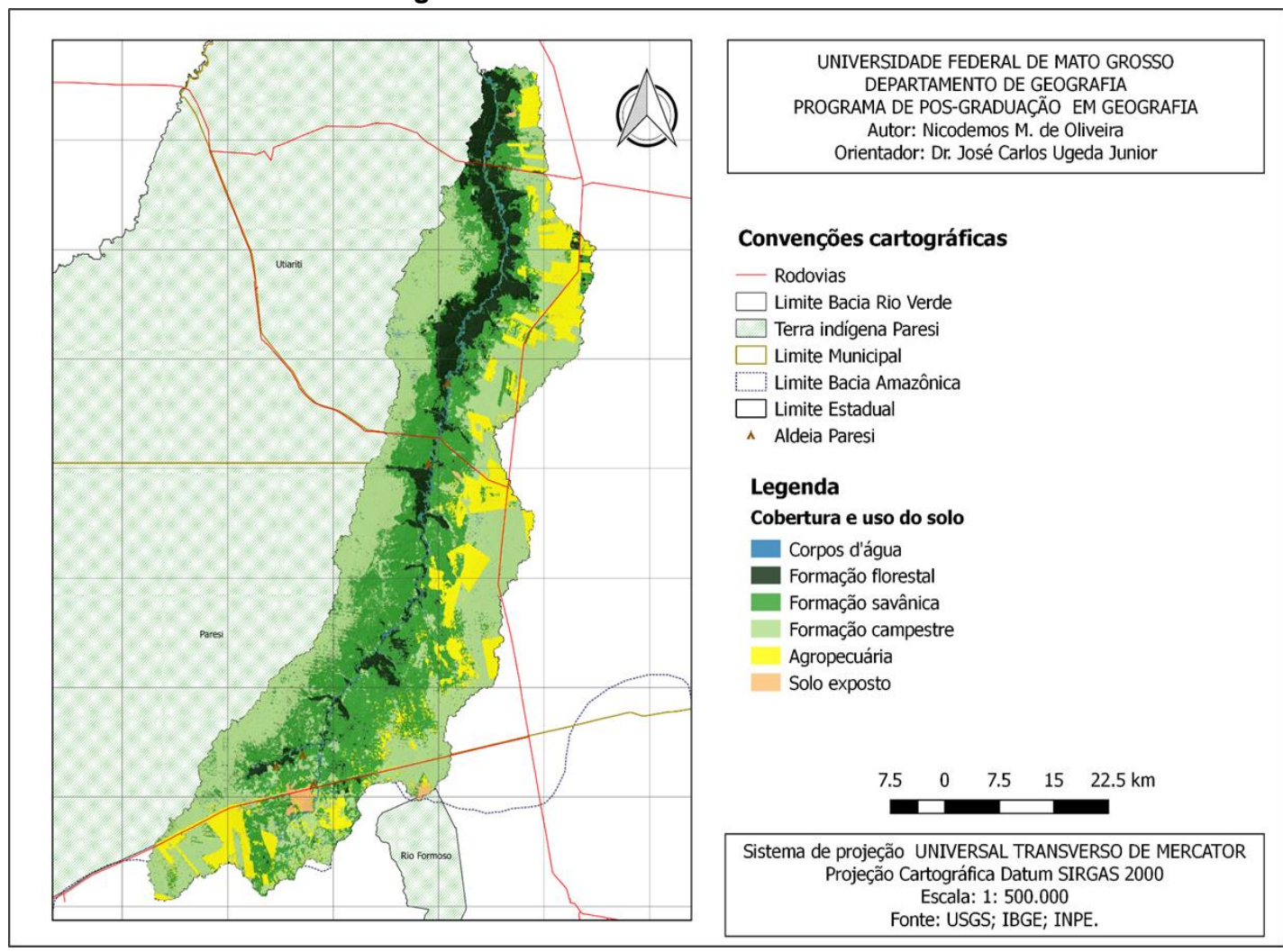

Fonte - OLIVEIRA (2018, p. 122).

Figura 2 - Uso e cobertura do solo 2016.

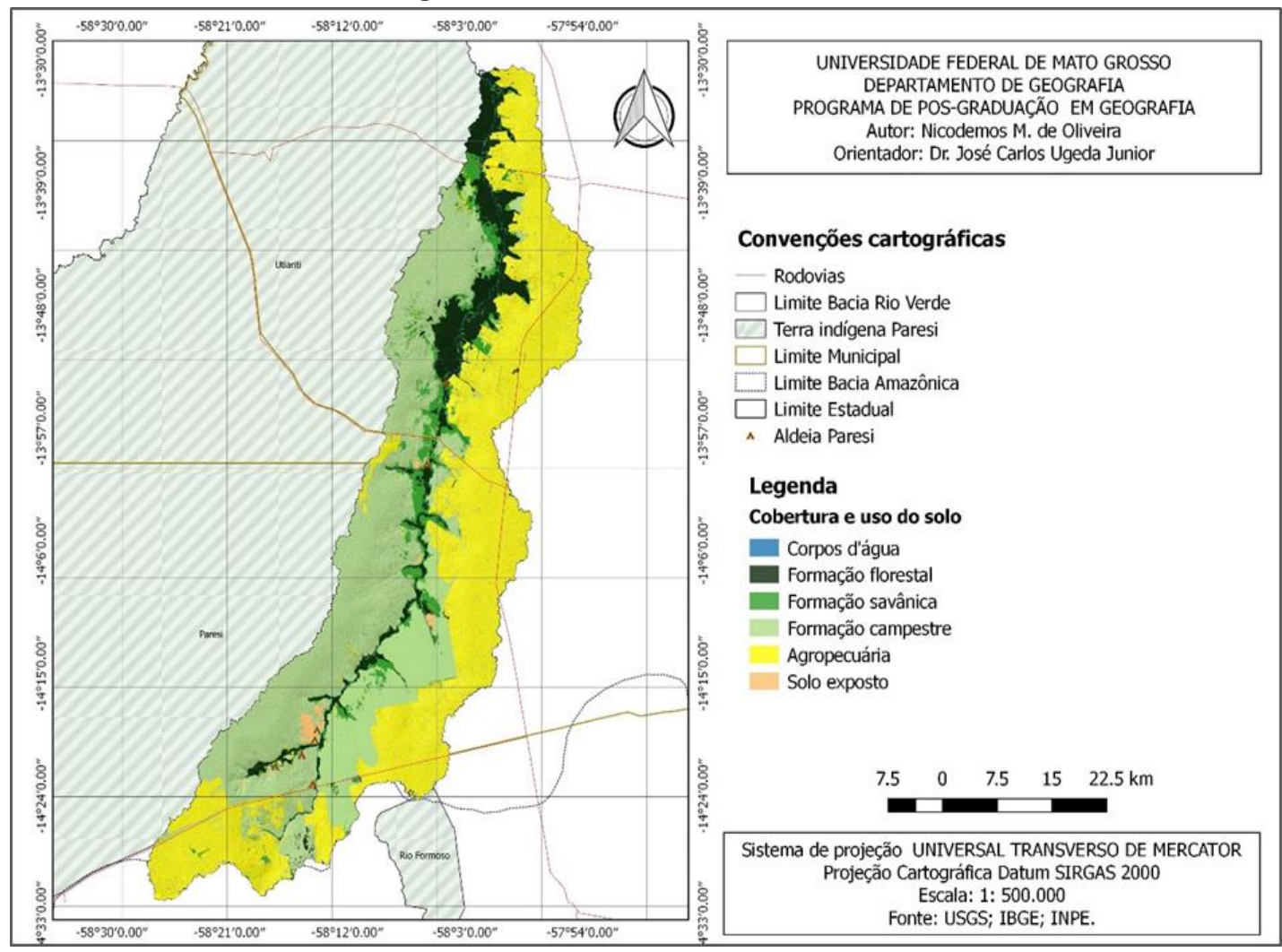

Fonte: OLIVEIRA (2018, p.123) 
Por outro lado, verifica-se que a fronteira do território indígena Paresi (delimitada pelo Rio Verde), assim como as demais terras indígenas do estado, ainda interrompe o mosaico geométrico das plantações. Ela aparece como uma linha de tensão, em que no lado externo encontra-se uma apropriação e transformação da natureza para a produção de commodities e do outro os indígenas ainda mantêm quase inalteradas as feições paisagísticas em seu território tradicional durante os últimos 30 anos.

O aumento de 408,24 km² de área de uso agrícola em 1986 para 1080,39 km² em 2016 demostra a dinamicidade do setor do agronegócio em Tangará da Serra e Campo Novo do Parecis para o período. O que consequentemente representou uma maior supressão da vegetação da bacia. Verificou-se ao longo dos trinta anos uma perda da vegetação natural na ordem de $27,45 \%$.

Em 1986 a vegetação representava $81,18 \%$ da área total da bacia, reduzida em 2016 para $53,73 \%$. E inversamente houve um aumento da área agrícola de $28,26 \%$, que se deu na quase totalidade na porção territorial localizada a margem direita do rio externa ao território indígena.

A formação savânica foi mais afetada, tanto pelo avanço da fronteira agrícola na área externa a terra indígena como pela descaracterização e fragmentação da vegetação natural em toda bacia, tendo uma redução drástica da sua área de $819,99 \mathrm{~km}^{2}$ para $128,47 \mathrm{~km}^{2}$.

Infere-se que, principalmente pela fragmentação da vegetação savânica com a supressão de suas plantas mais desenvolvidas e da manutenção dos indivíduos arbustivo-herbáceos, sua modificação também refletiu no comportamento espectral dessa vegetação.

Tal fato levou a recaracterização de um novo cenário de vegetação, de savânica para campestre. Por esse motivo esta última teve um aumento de área na bacia hidrográfica de $870,73 \mathrm{~km}^{2}$ em 1986 para 955,93 km² em 2016. Importante destacar que mesmo modificada a vegetação natural ocorre em grande parte dentro do território Paresi. Comparando-se a figura 1 com a figura 2, verifica-se que: diferente das áreas particulares, o território dos Haliti ainda mantém boa parte de sua cobertura vegetal natural.

No que se refere ao tipo de uso da cobertura da terra da bacia, atualmente predominam nas áreas externas ao território indígena a cultura de commodities agrícolas, com o cultivo da soja, do milho safrinha, algodão e porções de pasto com cobertura de braquiária.

As referidas culturas já ocupam praticamente toda região da bacia fora na reserva indígena. $\mathrm{E}$ também são encontradas também no interior do território indígena em regime de arrendamento, ocupando uma área indígena de aproximadamente $137 \mathrm{Km}^{2}$, correspondente a 2,3\% do território total do povo Paresi.

Nas aldeias separadas do território contíguo, a aldeia Rio Formoso possui $6,39 \mathrm{~km}^{2}$ de área plantada em regime de arredamento, apenas as aldeias Figueiras e Estivadinho não há presença de plantações de commodities. E no perímetro da bacia dentro do território indígena, existem aproximadamente $6,29 \mathrm{Km}^{2}$ de área agrícola plantada.

A situação do arrendamento, se deve a pressão exercida pelo agronegócio sobre os Pareci que teve dois objetivos principais: a construção de estradas atravessando as Terras indígenas, visando diminuir os custos de frete da soja e, posteriormente, o acesso ao próprio território indígena para o seu plantio. Diante dessa "situação, os Paresi tiveram dificuldades de resistir às investidas do agronegócio". (PASCA DAN, 2006. p. 630)

Ainda segundo Pasca Dan (2006) houve pressões dos sojicultores da região, com oferecimento de promessas, levaram por parte dos Haliti a aceitação, em 1984, da abertura da estrada cortando os territórios Utiariti e Paresi no sentido noroeste-sudeste. A condição acordada com os fazendeiros também revelara necessidades e posicionamentos distintos dos grupos locais frente a agronegócio, e que perduram até hoje.

Isso se deve a história do contato, Pasca Dan (2006), na qual as comunidades ao norte, mais favoráveis ao pacto, já exploravam seringais já desde os anos de 1940 sob a orientação de missionários jesuítas, levando-os a uma maior inserção na economia regional, e ainda tinham interesses na proteção e acesso aos seringais fora do território indígena, bem como à melhoria dos acessos da aldeia a cidade. 
Eles receberam apoio das comunidades ao sul da estrada, os menos afetados por ela tinham interesse no agronegócio e buscavam também ajuda para melhoria do atendimento à saúde. Já os mais afastados ao sudoeste e sul, a exemplo do território indígena Rio Formoso, demostraram resistência, sendo a maioria contra a abertura da estrada. Na ocasião as aldeias passavam por uma questão mais urgente que era a luta pela demarcação de seus territórios.

Pasca Dan (2006) esclarece que o universo Paresi atualmente é estruturado sob forma fronteiriça, a vida e os objetos tradicionais que a compõem se entrelaçam aos objetos característicos da cultura ocidental. E ao estarem em contato cotidianamente com a paisagem cercada pela agricultura moderna, e em meio a circulação de informações vindas de todas as partes do mundo, levam a criação de novas necessidades de consumo. São situações diversas a sua cultura que os moldam, impulsionam a ter novas formas de pensar e agir.

Os Paresi relatam que com a chegada dos não índios à Chapada do Parecis houve uma perda significativa de territórios considerados estratégicos à vida cotidiana tradicional. A exemplo, ficaram de fora muitas terras onde mantinham seus roçados, além dos locais de nascimento e morada dos elementos naturais usados na fabricação dos instrumentos sagrados, áreas de acampamentos de caça e perda de vários habitats dos animais de caça. A parcela restante encontra-se em áreas particulares, com o agravante de terem ainda fazendeiros impedindo os indígenas de realizarem a caçada e a pesca tradicional.

Porque tem fazendeiros que não reclamam com índio e fazem amizade com índio. Lá na fazenda que fica na cabeceira foi o índio que ajudou a abrir a fazenda. E lá na Querência também o índio que ajudou a abrir a fazenda. E na Branca também o índio ajudou a abrir a fazenda com serviço braçal. E vou contar uma história: Porque tudo o que a gente tinha ficou nas fazendas. $O$ Paresi tem a flecha de cura na cultura indígena. Aí uns tempos atrás vieram duas pessoas lá da aldeia Formoso. Nessa época eu tinha Toyota velha. Disseram: - "Eu quero que vocês levam nós até na cabeceira de Juba para tirar a taquara". Bom, então fui com eles, finado sogro também foi, as crianças também foram, nós procuramos a cabeceira, depois escurecendo, de repente nós encontramos o fazendeiro. Aí o fazendeiro perguntou: "O que vocês estão fazendo aqui?". - "Nós estamos querendo pegar a taquara conforme a nossa cultura. Porque essa taquara fica só aqui, só nessa cabeceira, e outro lugar tem, mas não é como essa". E ele fala: - "Aqui é propriedade particular, vocês têm que respeitar". - "Nós estamos entrando com todo o respeito, não vamos pegar nada da sua fazenda". - Ele começou a falar: "Ah bom, amanhã vocês podem entrar, só hoje podem voltar e dormir lá na BR". Então voltamos e dormimos na BR. E no outro dia nós fomos tirar. Juntou três pessoas fortes e tiraram. Então, o medo deles é porque eles criam o gado né. $E$ tem medo da gente matar o gado deles. [...] tem que conversar bem com eles. Aí você tira todo esse acampamento de caça do Paresi. (LIDERANÇA INDÍGENA, ALDEIA ÁFRICA, 2017).

Com a fatídica perda de boa parte dos territórios de caça e roçado eles procuram por alternativas para suprir suas necessidades cotidianas. E ao mesmo tempo resistem, se voltam ao passado para manterem vivas as necessidades das tradições culturais que os diferenciam da sociedade ocidental, e que dão a forma, mantem a coesão dos seus territórios pelas territorialidades intrínsecas ao povo Haliti.

Embora os Paresi tenham a parceria agrícola em 2,3\% do seu território para o cultivo de commodities, seu território ainda continua atuando como uma barreira sociocultural frente ao avanço das atividades agropecuárias, principal responsável pela fragmentação e supressão da vegetação na bacia hidrográfica do Rio Verde e Chapada dos Parecis.

Onde aparecem a nível local os conflitos de uso da unidade da paisagem, pelas práticas sociais originárias de necessidades culturais e motivações econômicas distintas entre as sociedades Paresi e os não indígenas. E na qual a interferência da primeira sobre a natureza demonstrou ser muito menos agressiva que a segunda, demonstrado pela heterogeneidade da paisagem no interior do território indígena. 
As roças tradicionais são um exemplo de agrodiversidade, importante para manutenção da biodiversidade, Maciel (2010). A alta diversidade das roças indígenas é elemento imprescindível para a segurança alimentar desses povos, atuam na estabilidade de seus sistemas agrícolas. Além disso, "a diversidade genética, manejada por agricultores tradicionais, indígenas ou não indígenas, é fruto de um longo e diversificado processo iniciado com a domesticação de um recurso silvestre". (MACIEL, 2010 p.59)

A paisagem da bacia se encontra em um processo de mudanças socioambientais onde locais, dotados de características consideradas como fundamentais pelos indígenas para manutenção das atividades tradicionais da aldeia, foram apropriados ao longo dos anos por particulares e transformados em lavouras. São mudanças visualizadas também em impactos socioambientais, como a diminuição de território (o que é mais grave para algumas aldeias como Estivadinho e Figueiras), na homogeneização do uso do solo, e ainda em decorrência da chegada de diversos elementos da modernidade no dia-a-dia da aldeia. Uma realidade que destoa do aprendizado requerido pelos anciões Haliti, que enfrentam dificuldades para passar aos mais jovens um conhecimento ímpar, complexo e intrigante do modo de vida do seu povo.

As paisagens indígenas são encontros de vários seres humanos e outros seres dotados de humanidade, são ao mesmo tempo lugares e sujeitos. Sujeitos se metamorfosearam, as vezes em sinal de sacrifício, fornecendo a paisagem uma estrutura, morfologia e dinâmica biológica ao modo de ver tradicional, conforme a história mítica do surgimento da mandioca:

\begin{abstract}
Essa mandioca surgiu dos ancestrais, de muito tempo. Uma senhora casou com dois homens, o nome dela Kukutero. E a filha dela Atulu-tse, mas ela ficou cheio de feridas, aí os pais dela não gostaram dela. Quando ela fala: "Pai!"..., mas os pais dela só assoviam. Aí nesse caso ela sentiu tristeza na vida dela. Aí falou para a mãe kukutero: "Você me planta perto de árvore". Aí foi plantar, mas não deu certo. Deu tudo reação de alergia nela. Aí foi a mãe dela. "Você tem que me mudar de lugar". Um monte de Safero, um monte de formiga né. Aí plantou ali, plantou assim metade do corpo. Também as formigas não deixavam ela sossegada, sempre mudando né. A mãe veio de novo e não deu certo. Agora você me leva no mato mesmo. Então plantou ali. E orientou a mãe: "Agora vocês voltem para casa. Quando eu gritar você não olha para trás, você segue para frente sem olhar. Eu vou gritar o grito de flautas secretas, aí você não pode voltar, não pode olhar para trás". Aí a mãe plantou e foi. Quando tava perto ainda começou a gritar, o grito de flauta secreta. Ai a mãe olhou, viu que cresceu a mandioca muito alto, mais alto do que o mato de árvore. Quando olhou a mandioca abaixou. Aí no outro dia a mãe foi e mandioca já está nascendo, já tá grande. Aí começou a tirar a raiz. E ela falou: "deixa me retirar primeiro da mandioca daí você tira a raiz. Ai a mãe tirou a raiz. Sempre assim, todo dia. E alguém viu que Kukutero tá fazendo isso, que acordando cedo, de madrugada com aquela alegria, socando o pilão a mandioca para fazer chicha. Esse alguém viu. "Eu vou acompanhar o rastro dela para ver o que tá acontecendo aí". Ela foi lá vê a mandioca. E ela falou: "Mãe é ser você mesmo?" Aí não respondeu nada. Começou a cortar a raiz antes dele retirar do pé da mandioca. Aí começou a gritar. E a mãe já correu, porque viu. E já tava tudo esparramado naquela água de mandioca. Tudo esparramado. Aí mandioca ficou mais pequeno ainda. E assim que surgiu mandioca: De uma menina! (LIDERANÇA HALITI, ALDEIA ÁFRICA, 2017).
\end{abstract}

Já a sociedade ocidental, representada neste local pelos fazendeiros, estes nunca chegaram a conhecer de fato a paisagem em suas nuances. Pois de acordo com o estudo, pela forma como a desconfiguram, impuseram a ela uma cobertura homogênea pelo uso e ocupação do solo para a agricultura em larga escala das commodities. No momento em que se torna geometrizada, acaba por debilitar e apagar os elementos que compõem as heranças culturaisnaturais, universais e particulares da vida social, sua história.

A manutenção e restauração da paisagem indígena depende da flexibilidade territorial, da heterogeneidade do geossistema. Enquanto isso, outra paisagem vai sendo imposta e se abstraindo da ordem assimétrica natural. Dela se espera um continuo de fenômenos naturais ordenados, assim como uma organização e cobertura do espaço homogênea e previsível.

$\begin{array}{lllll}\text { Caminhos de Geografia } & \text { Uberlândia-MG } & \text { v. 29, n. } 69 & \text { Mar/2019 } & \text { p. 282-292 Página } 290\end{array}$


Pronta, segue um fluxo único de troca estabelecido, o dos nutrientes do solo pelos resultados da produção agrícola. Assim, quando mais lineares e previsíveis forem os fenômenos (a natureza aparece aqui como um obstáculo que continuamente projeta um novo equilíbrio geossistêmico pela diversidade) mais facilitada estará a produção, pois não se visualiza uma necessidade do uso diverso do espaço, a produção da natureza em troca de mercadoria já por si basta para as forças produtivas abastecerem o mercado.

Por outro viés, seria uma paisagem resultante de processos de objetivação dos seus elementos naturais e sociais. Os fazendeiros então se satisfazem como sujeito no momento que enxergam uma prática objetiva para a paisagem, "se conhece objetivamente quando consegue se ver "de fora", como um "isso". Nosso jogo epistemológico se chama objetivação; o que não foi objetivado permanece irreal e abstrato. A forma do Outro é a coisa". (VIVEIROS DE CASTRO, 2004, p. 246)

Na perspectiva dos haliti, o demiurgo Wazare já tinha alertado o irmão dele, o Deus dos imóti (Tohaikarrore) que não seria bom para os seus filhos conviverem muito próximos aos dele. Por esse motivo pediu a Tohaikarrore que levasse os imóti para morar depois do Rio Grande (mar). Porém, mesmo Tohaikarrore levando seus filhos para o além-mar, suas crias o desobedeceram e vieram parar aqui nas Américas, ocupando a chapada do Parecis, território de vários povos indígenas. $\mathrm{E}$ desde então os indígenas e as formas de vida presentes na paisagem que compreende o universo haliti não tiveram muita paz.

\section{CONSIDERAÇÕES FINAIS}

Realizar uma análise integrada da paisagem se mostrou tarefa complexa desde o início. E ao estar diante de uma demanda social de um grupo indígena em que se desconhece sua relação com a natureza engrandece ainda mais o desafio da pesquisa.

Ao primeiro encontro com paisagem na aldeia o pesquisador foi apresentado ao problema de assoreamento do Rio Verde, isso foi o percebido no momento. O que o levou a focar-se em escutar dos Paresi essa aflição para resolver a questão ambiental pela morfogênese do processo.

No entanto, a geoecologia da Paisagem trazendo a perspectiva sistêmica anseia por conexões, por uma integridade da unidade da paisagem. Essa motivação levou a procura, ao levantamento dos componentes que se inter-relacionam e revelam a dinâmica da paisagem da bacia hidrográfica do Rio Verde.

Diante de uma formação antropo-natural da paisagem Rodriguez, Silva e Cavalcanti (2004) a pesquisa pode se desenvolver retirando-se do foco da dinâmica física e trilhando para o caminho das condições sociais e culturais que modificam o meio, ou seja, está se diante de uma natureza modificada, ou segunda natureza.

O que significou adentrar em discussões dialéticas, em uma conversa entre a sociedade e a natureza, porém não se deixou de lado as estruturas físicas e suas dinâmicas na composição da paisagem, pois tratou-se de uma análise integrada da paisagem. Demonstrado pelo inventariado dos principais elementos da paisagem, imprescindíveis para 0 atesto de limites e fragilidades ambientais, principalmente no que se diz respeito ao uso e ocupação do solo pelos fazendeiros.

Os danos ambientais sobre o Rio Verde foram então inseridos na dinâmica socioambiental da paisagem. Levando o ponto central da discussão para a relação sociedade-natureza. Nesse viés que entrou em cena a integração da epistemologia materialista e crítica com as questões ambientais. E pode ser colocado as duas visões de mundo de ambas as sociedades indígenas e não indígenas na produção do espaço e transformação da paisagem.

E como a abordagem da relação sociedade natureza é também ontológica, a crítica se voltou novamente a epistemologia do pensamento geográfico para adentrar na discussão em torno das territorialidades que compõem o universo indígena Paresi e da sociedade não indígena.

O pensamento de ambas as sociedades, que moldam o diálogo do ser e agir no espaço, revelaram então antagonismos, desigualdades e contradições espaciais. Frutos de realidades ontológicas distintas, possuidores de dimensões simbólicas, ideológicas que se chocam, aparecem nas tensões territoriais, nas territorialidades que se impõem e se intimidam diante da voracidade da outra.

Ao final cada uma reclama a paisagem que lhe espelha, porém em algum lugar elas se encontram, comungam uma interseção, onde se espera o equilíbrio da paisagem. Ao que se percebe pelas

$\begin{array}{lllll}\text { Caminhos de Geografia } & \text { Uberlândia-MG } & \text { v. 29, n. } 69 & \text { Mar/2019 } & \text { p. 282-292 Página } 291\end{array}$


entrevistas, pelos resultados de uso e ocupação do solo, e por conceberem a natureza como una, uma das sociedades parece ter superado há um bom tempo, mesmo vivendo sob forte pressão externa, a dicotomia da sociedade natureza, ainda tão presente na sociedade ocidental, assim o equilíbrio da paisagem caminha mais próximo da cultura indígena.

\section{AGRADECIMENTOS}

De forma saudosa, agradeço aos indígenas pela confiança no aceite do desafio de pesquisar a paisagem e o modo de vida tradicional em seus territórios. Sou muito grato Fundação Nacional do Índio - FUNAI Brasília pela fineza e celeridade com o processo de permissão para acesso e execução da pesquisa em território indígena. Meus sinceros agradecimentos a todos os envolvidos.

\section{REFERÊNCIAS}

BERTRAND, G. Paisagem e geografia física global: um esboço metodológico. Revista IGEOG/USP. Caderno de Ciências da Terra. São Paulo, USP, n. 13, 1971. pp. 1-27.

EMBRAPA. Agência de Informação Embrapa. Bioma Cerrado. Disponível em: <http://www. agencia.cnptia.embrapa.br/Agencia16/AG01/arvore/AG01_96_10112005101956.html>. Acesso em: 27 jun. 2017.

GIANNINI, Isabelle Vidal. Os índios e suas relações com a natureza. Índios no Brasil. Brasília: Ministério da Educação e do Desporto, p. 145-152, 1994.

GONÇALVES, Carlos Walter Porto. Da geografia às geo-grafias. Um mundo em busca de novas territorialidades. 2002.

GONÇALVES, Carlos Walter Porto. Os descaminhos do meio ambiente. 14 ed. 148 p. São Paulo: Contexto, 2006.

MACIEL, Márcia Regina Antunes. Raiz, planta e cultura: as roças indígenas nos hábitos alimentares do povo Paresi, Tangará da Serra, Mato Grosso. Brasil. 2010.

OLIVEIRA, Nicodemos M. Análise integrada da bacia hidrográfica do rio Verde: a dualidade na relação sociedade-natureza entre os indígenas Paresi e os fazendeiros do entorno sobre a paisagem. 2018. Dissertação (Mestrado em Geografia). Universidade Federal de Mato Grosso.

PASCA, Dan. Nos Tentáculos do Agronegócio. In: RICARDO, Beto, RICARDO, Fany. Povos Indígenas no Brasil: 2001 / 2005. São Paulo: Instituto Socioambiental, 2006, p. 629-633.

RODRIGUEZ, José Manuel Mateo; DA SILVA, Edson; CAVALCANTI, Agostinho Paula Brito. Geoecologia das Paisagens: uma visão geossistêmica da análise ambiental. Editora UFC Fortaleza, Ceará, v. 222, 2004.

SANTOS, Milton. A Natureza do Espaço: Técnica e Tempo, Razão e Emoção. 4ªed. São Paulo: Edusp, 2006.

SANTOS, Milton. Metamorfoses do espaço habitado: fundamentos teóricos e metodológicos da Geografia. 6⿳亠丷厂 edição. São Paulo: Edusp, 2008.

SMITH, N. Desenvolvimento Desigual. Rio de Janeiro: Bertrand Brasil, 1987.

VIVEIROS DE CASTRO, Eduardo. Perspectivismo e multinaturalismo na América indígena. 2004.

Recebido em: 22/02/2018

Aceito para publicação em: 08/052019

$\begin{array}{lllll}\text { Caminhos de Geografia } & \text { Uberlândia-MG } & \text { v. 29, n. } 69 & \text { Mar/2019 } & \text { p. 282-292 Página } 292\end{array}$

